\title{
5 JAHRE ZAA IN BUNT - EIN RÜCKBLICK
}

inen Artikel in ein Titelbild zu übersetzen ist oft eine
Herausforderung. Das Thema soll sichtbar werden, das Bild ein einprägsamer Hingucker sein. Das Copyright zu beachten ist inzwischen ein zeitintensives Geschäft und das Resultat keineswegs vorherbestimmbar. Wenn möglich, habe ich daher auf eigene Ressourcen zurückgegriffen.
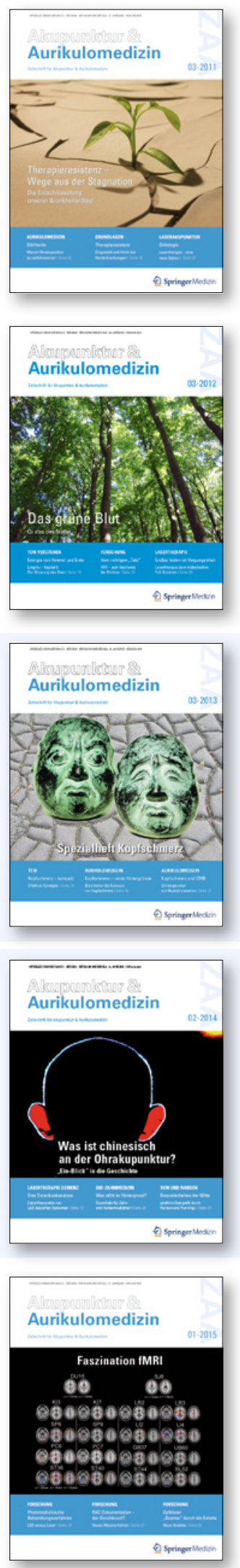
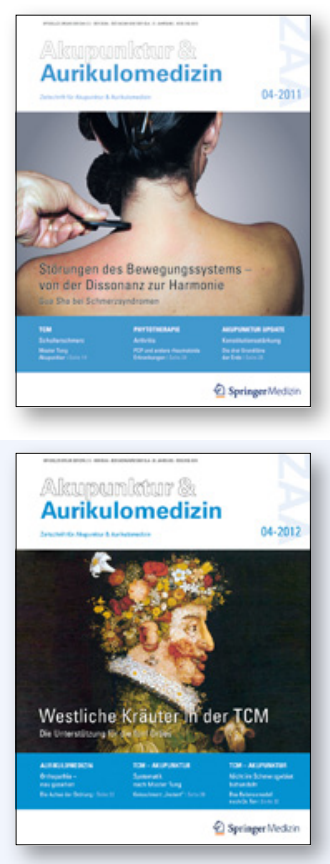

Heft 3-13

Eine besondere Herausforderung, aber auch ein kreativer Prozess ist das Erstellen eines Titelbilds aus eigenen Ressourcen. Der Hintergrund: ein Foto des außergewöhnlichen Asphaltmusters auf der Schönhauser Allee, im Vordergrund die Ge-

\section{Heft 2-14}

Da hat der Fotograf, den ich nach einigen Recherchen ausfindig gemacht hatte, sogar noch eine hochwertigere Version zur Verfügung gestellt und auf jegliches Honorar verzichtet. Ein Glücksfall.

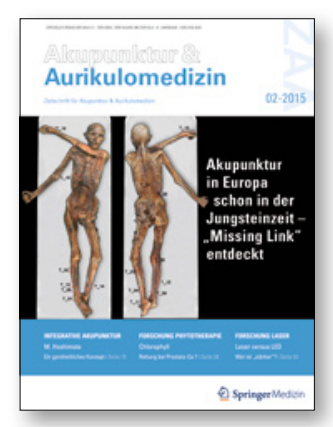

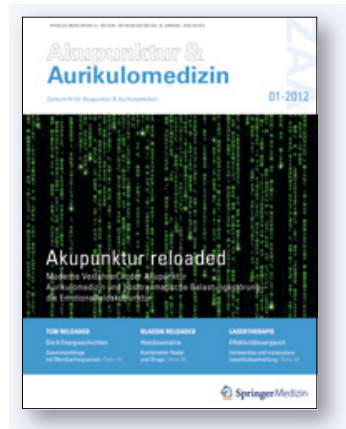

\section{Heft 4-12}

Der Frühling (La Primavera) von Arcimboldo ist frei, da der Maler bereits 1593 das zeitliche segnete und 1563 dieses herrliche Gemälde schuf. Es ist im Original zu bewundern in der Real Academia de Bellas Artes de San Fernando, Madrid, Spanien.

sichter einer ca. 5-6 cm hohen Bronze-Figur mit insgesamt 4 verschiedenen Gesichtern, Mitbringsel von einer Chinareise aus Lijiang, einer Stadt in Yunnan mit der am besten erhaltenen Altstadt Chinas, interessant auch wegen der multikulti Bevölkerungsmischung.
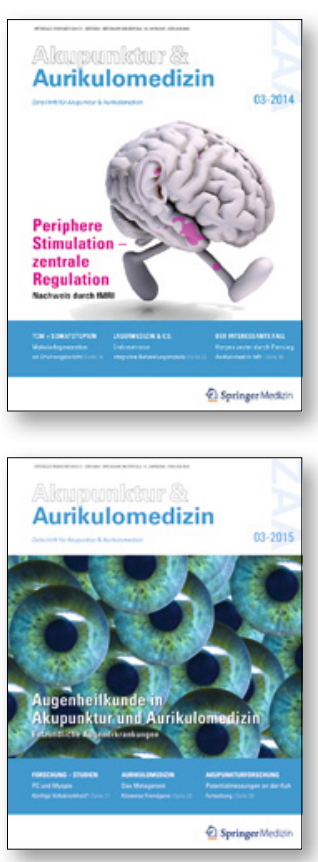

\section{Heft 1-12}

Die Matrix, bestehend aus chinesischen Schriftzeichen zu finden war purer Zufall und passte perfekt für unsere Titelstory.

Heft 2-12

Der beeindruckende Wasserfall rauschte im Naturpark Jiuzhaigou im nördlichen Sichuan
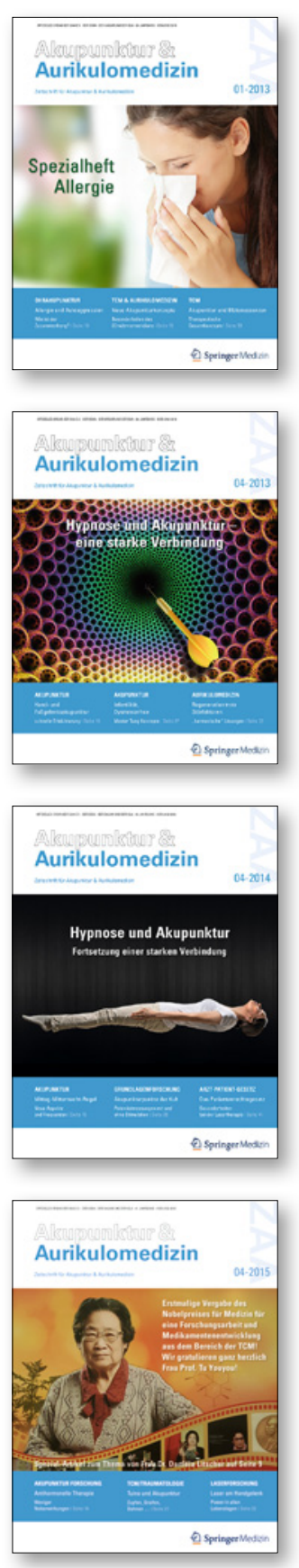

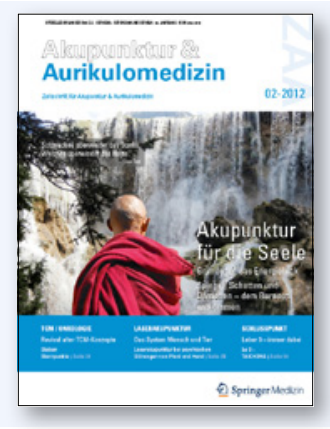

(⿸丆口
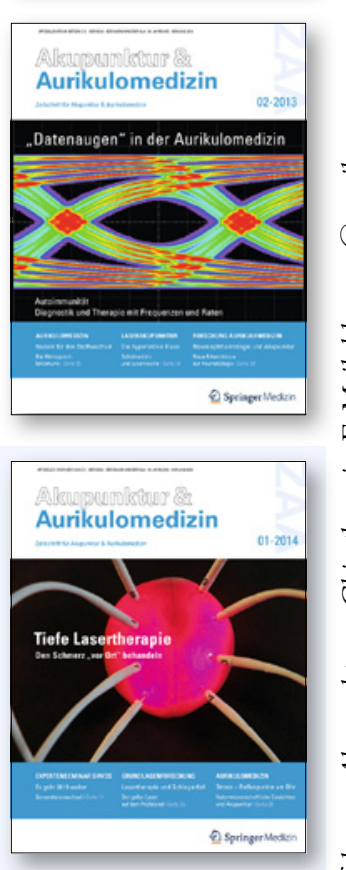

$\Delta$ Heft 1-14

Ein Pfirsich leuchtet im Licht der Laserkabel eines Laserneedle-Gerätes. Der Laser hat das Fotoshooting gut überstanden.

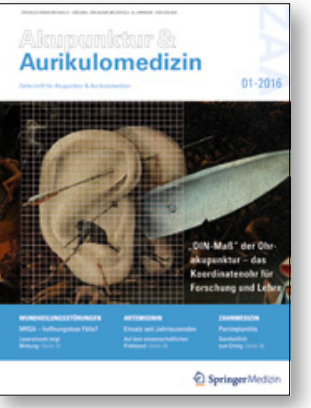

